\title{
Levothyroxine Formulations: Pharmacological and Clinical Implications of Generic Substitution
}

Salvatore Benvenga · Allan Carlé

Received: August 16, 2019 / Published online: September 4, 2019

(C) The Author(s) 2019

\section{ABSTRACT}

Oral levothyroxine (LT4) is the standard therapy for patients with hypothyroidism. Oral LT4 is available in several formulations, including tablets, soft gel capsules and oral solution. Multiple brand-name and generic LT4 tablets are available. In the US, the Food and Drug Administration (FDA) has developed a protocol for establishing bioequivalence of LT4 formulations based on serum thyroxine (T4) levels after a single oral dose administered to healthy

Enhanced Digital Features To view enhanced digital features for this article go to https://doi.org/10.6084/ m9.figshare.9707564.

S. Benvenga $(\square)$

Endocrinology Section, Department of Clinical and

Experimental Medicine, University of Messina,

Messina, Italy

e-mail: s.benvenga@live.it; sbenvenga@unime.it

S. Benvenga

Master Program on Childhood, Adolescent and

Women's Endocrine Health, University of Messina,

Messina, Italy

S. Benvenga

Interdepartmental Program of Molecular and Clinical Endocrinology and Women's Endocrine Health, University Hospital, AOU Policlinico G.

Martino, Messina, Italy

\section{A. Carlé}

Department of Endocrinology and Internal Medicine, Aalborg University Hospital, Aalborg, Denmark volunteers. This protocol has been criticized by professional endocrinology associations for using healthy individuals and ignoring serum thyroid-stimulating hormone (TSH) levels. In addition, the protocol did not initially correct for baseline T4 levels, although this was changed in a later version. There are concerns that the FDA's protocol could allow products with clinically significant differences in bioavailability to be declared therapeutically equivalent and interchangeable. Once a generic LT4 has been shown to be bioequivalent to a brandname LT4, it may be substituted for that brandname LT4 with no need for dose adjustment or follow-up therapeutic monitoring. Often, the substitution is made by the pharmacy without the physician's knowledge. Even small differences between LT4 formulations can cause significant changes in TSH levels. This may be a particular concern in vulnerable populations, including elderly, pregnant, and pediatric patients. Problems that can be encountered when switching between formulations or when original products are reformulated are discussed in this review. These problems include altered efficacy and adverse events, some of which can be caused by excipients. Patients should be maintained on the same LT4 preparation if possible. If the LT4 preparation is changed, TSH levels should be evaluated and, if necessary, the dose of LT4 adjusted.

Funding: Merck. 
Plain Language Summary: Plain language summary available for this article.

Keywords: Drug substitution; Endocrinology; Hypothyroidism; Pharmacokinetics; Levothyroxine; hormone

\section{PLAIN LANGUAGE SUMMARY}

Orally administered levothyroxine (LT4) is the standard treatment for hypothyroid patients. Several different LT4 products are available. Sometimes, pharmacists may substitute a patient's usual LT4 product for a less expensive one, especially if this is the policy of the organisation that is paying for the medicine (e.g., health insurer or public health provider). Because even small differences between LT4 products can have significant effects on how well the drug works, or the types of side effects it may cause, most clinical practice guidelines recommend that patients stay on the same LT4 preparation if possible. If the patient needs to switch to a new LT4 product, physicians should ensure that the dose is adjusted to suit the patient.

\section{INTRODUCTION}

Thyroid hormone replacement therapy with oral levothyroxine (LT4) is the standard treatment for patients with hypothyroidism [1-3]. The goals of treatment include resolution of symptoms and signs of hypothyroidism and normalization of circulating thyroid-stimulating hormone (TSH) levels [3]. Orally administered LT4 is available in several formulations (including tablet, soft gel capsule and liquid formulations) $[2,4]$, and LT4 tablets are available in multiple branded and generic forms [2]. The traditional tablet formulation contains LT4 sodium, a stable salt, and a variety of inactive excipients, the composition of which may affect tablet stability and pharmacokinetics [4-8].

The US Food and Drug Administration (FDA) defines a 'generic drug' as a medication that has the same dosage form, safety, strength, route of administration, quality, performance characteristics and intended use as an already marketed brand-name medication [9]. The European Medicines Agency (EMA) defines generic drugs as those that have the same qualitative and quantitative composition of active substances and the same pharmaceutical form as the reference drug and whose bioequivalence with the reference drug has been demonstrated by appropriate bioavailability studies [10]. With regard to generic and branded LT4 preparations, endocrinologists around the world differ in their preferences. According to a survey of 880 members of The Endocrine Society (TES), the American Thyroid Association (ATA) and the American Association of Clinical Endocrinologists (AACE), 49.9\% of respondents preferred brand-name LT4, while $49.3 \%$ preferred generic LT4. However, among European members, who represented $9.2 \%$ of respondents, the proportion of those who preferred a brand-name drug was 58.8\% [11].

At present, the FDA uses serum thyroxine (T4) levels to establish the bioequivalence of LT4 products [12]. Based on the FDA criteria for bioequivalence (described in detail in the section "Bioequivalence and interchangeability"), substitution between bioequivalent generic and brand-name LT4 can be automatically performed with no need for dose adjustment. There is ongoing debate around concerns that the currently used pharmacokinetic approach for assessing the bioequivalence of LT4 products could allow products with clinically significant differences in bioavailability to be declared therapeutically equivalent and interchangeable [3, 12-19]. Therefore, the ATA, the ES and the AACE have issued a joint statement encouraging consistent use of the same branded or generic LT4 formulation in individual patients (i.e., patients should not be regularly switched from one brand to another, from a branded to a generic product or from a generic product to another generic product) [13]. These recommendations have since been reinforced by guidelines from the Endocrine Society of Australia, the European Thyroid Association and Thyroid Federation International [3, 20, 21], and are summarized in Table 1 . If a switch to 
Table 1 Summary of practices for physicians and patients, with regard to switching levothyroxine formulations, that were proposed in international/national guidelines/statements $[3,13,20,21]$

For physicians

Patients should be maintained on the same brand name of levothyroxine product

If the brand of levothyroxine medication is changed from one brand to another brand, from a brand to a generic product or from a generic product to another generic product:

Patients should be re-evaluated and retested by measuring serum TSH in 6 weeks;

The drug should be retitrated as needed

For patients

Use the same brand of thyroid medication throughout your treatment

Thyroid disease often requires lifelong therapy and is best managed with consistent and precise treatment with the same brand of thyroid hormone

Your doctor may change your dose of thyroid hormone, but the brand of your thyroid hormone medication should always stay the same

When you go to the pharmacy, do not change the brand of your thyroid medication without checking with your doctor

You should not change your dose from one brand of thyroid medication to another, from your brand of thyroid medication to a generic product, or from one generic product to another without first checking with your doctor

If your doctor changes the type of thyroid medication you are taking, you will need to have repeat blood tests and visits to your doctor to make sure that you are on the correct dose. Your dose may need to be readjusted if your thyroid medication is changed

another LT4 formulation is made (for instance, because the waiting time between LT4 ingestion and breakfast is an issue for the patient or because the patient is co-ingesting drugs known to impair the intestinal absorption of LT4), repeat thyroid function testing is recommended (i.e., serum TSH testing within 4 weeks to determine whether dose adjustment is required) $[3,13,19,21]$.

Switching was considered to be a particular concern in vulnerable populations, including elderly, pregnant and pediatric patients $[3,13]$, especially since these patients are often excluded from the studies undertaken to establish bioequivalence [10]. This review describes problems that can be encountered when switching between formulations or when original products are reformulated.

\section{METHODS}

In December 2018, the PubMed database was searched for articles of potential interest using "levothyroxine" in combination with each of the following search terms: "interchangeability", "bioequivalence", "formulations" and "generic". These combinations returned 10, 120, 128 and 79 entries, respectively. The titles and abstracts of English-language articles identified through the search were then reviewed to determine relevance. Furthermore, the reference lists of the relevant articles were used to identify additional literature. This article is based on previously conducted studies and does not contain any studies with animals performed by any of the authors. Some of studies cited include analyses, or studies with human 
participants, performed by the authors and completed prior to the initiation of this manuscript.

\section{BIOEQUIVALENCE AND INTERCHANGEABILITY}

Bioequivalence of LT4 formulations is defined as the absence of a significant difference in bioavailability, expressed in terms of the maximum concentration $\left(C_{\max }\right)$ or area under the curve (AUC), of the active ingredient of a drug product when administered at the same molar dose in healthy volunteers $[14,18,22]$. A specific LT4 pharmacokinetic protocol for bioequivalence has been developed by the FDA $[2,23]$. In this protocol, a single oral dose of $600 \mu \mathrm{g}$ of LT4 is administered to healthy volunteers [12]. The 90\% confidence interval (CI) for test/reference product geometric mean AUC and $C_{\max }$ ratios of serum $\mathrm{T} 4$ must be in the $80-125 \%$ range [14]. Note that the $90 \%$ CI for narrow therapeutic index drugs is $90-111.1 \%$, and LT4 is often considered a narrow therapeutic index drug $[13,14,24]$. The FDA assigns an $\mathrm{AB}+$ number $\mathrm{TE}$ code to LT4 tablets (Table 2) [25-33]. Products with the same TE code are considered therapeutically equivalent [32].

The LT4 bioequivalence protocol produced by the FDA has been criticized by professional endocrinology associations. In their joint letter, the ATA, the ES and the AACE pointed out that pharmacokinetic assessments are not suitable for biologics and that the protocol does not include TSH assessment [13]. Omitting TSH is illogical, considering that it is the most sensitive and easily measurable biochemical target of thyroid hormone action and because of its importance for monitoring the adequacy of LT4 treatment [14, 24]. Yet, we think that with a half-life of approximately $1 \mathrm{~h}$, a minimum of four measurements (two baseline, one intermediate and one final) could be added to the FDA protocol with little extra cost incurred. In addition, the FDA protocol did not initially include correction for baseline T4 levels [12]. According to the 2014 ATA guidelines, a more appropriate measure of bioequivalence would be based on T4, triiodothyronine (T3) and TSH levels after daily administration for at least 4-6 weeks conducted in athyreotic individuals [3]. These guidelines refer to research conducted by Mayor and colleagues [34], who re-analyzed data previously published by Dong and colleagues [35], showing that LT4 products considered to be both pharmacokinetically and therapeutically bioequivalent were not in fact therapeutically bioequivalent when correction for baseline T4 was applied [34]. The FDA later included correction for baseline T4 in its protocol [12]. Another drawback of FDA's protocol is the use of healthy volunteers. In a study that included 4 patients with goiter, 12 euthyroid controls and 10 primary hypothyroid controls who were administered LT4 1000- $\mu$ g tablets, serum T4 curves in the two control groups were shown to be not entirely superimposable [36].

There are no equivalent European guidelines for the demonstration of LT4 formulation bioequivalence, but the FDA bioequivalence guidelines for LT4 are referred to in European countries [37, 38]. Instead, the relevant European guideline is the 2010 European Medicines Agency Guideline on the Investigation of Bioequivalence [10]. This guideline is focused on immediate-release formulations of chemical entities with systemic action, while modifiedrelease, transdermal and orally inhaled formulations, as well as biologicals, are not covered. According to this Guideline, medicinal products containing the same active substance are considered to be bioequivalent "if they are pharmaceutically equivalent or pharmaceutical alternatives and their bioavailabilities (rate and extent) after administration in the same molar dose lie within acceptable predefined limits. These limits are set to ensure comparable in vivo performance, i.e., similarity in terms of safety and efficacy" [10]. Medicinal products are considered to be pharmaceutically equivalent if they "contain the same amount of the same active substance(s) in the same dosage forms that meet the same or comparable standards" [10]. Of note, pharmaceutical equivalence does not always imply bioequivalence because differences in excipients and the manufacturing process can affect pharmacokinetics [10]. 
Table 2 FDA therapeutic equivalence ratings for currently available levothyroxine tablet products [25-33]

\begin{tabular}{llll}
$\begin{array}{l}\text { Levothyroxine } \\
\text { tablet product }\end{array}$ & $\begin{array}{l}\text { Reference } \\
\text { listed drug }^{\mathbf{a}}\end{array}$ & $\begin{array}{l}\text { Therapeutic } \\
\text { equivalence } \\
\text { code }\end{array}$ & Inactive ingredients $^{\mathbf{c}}$ \\
\hline $\begin{array}{c}\text { Brand name } \\
\text { Unithroid }\end{array}$ & Yes & $\mathrm{AB} 1, \mathrm{AB} 2, \mathrm{AB} 3$ & $\begin{array}{c}\text { Acacia, colloidal silicon dioxide, corn starch, lactose, magnesium } \\
\text { stearate, microcrystalline cellulose, sodium starch glycolate }\end{array}$ \\
Synthroid & Yes & $\mathrm{AB} 1, \mathrm{AB} 2$ & $\begin{array}{c}\text { Acacia, confectioner's sugar (contains corn starch), lactose } \\
\text { monohydrate, magnesium stearate, povidone, talc }\end{array}$ \\
Levoxyl & Yes & $\mathrm{AB} 1, \mathrm{AB} 3$ & $\begin{array}{c}\text { Calcium sulfate dehydrate, croscarmellose sodium, magnesium } \\
\text { stearate, microcrystalline cellulose, sodium bicarbonate }\end{array}$ \\
Levo-T & No & $\mathrm{AB} 1, \mathrm{AB} 2, \mathrm{AB} 3$ & $\begin{array}{c}\text { Magnesium stearate, microcrystalline cellulose, colloidal silicone } \\
\text { dioxide, sodium starch glycolate }\end{array}$ \\
Euthyrox & No & $\mathrm{AB} 2$ & $\begin{array}{c}\text { Citric acid anhydrous, corn starch, gelatin, magnesium stearate, } \\
\text { mannitol, sodium croscarmellose }\end{array}$
\end{tabular}

Generic

\begin{tabular}{|c|c|c|c|}
\hline $\begin{array}{l}\text { Levothyroxine } \\
\text { sodium } \\
\text { (Mylan) }\end{array}$ & No & $\begin{array}{l}\mathrm{AB} 1, \mathrm{AB} 2, \mathrm{AB} 3 \\
\mathrm{AB} 4\end{array}$ & $\begin{array}{l}\text { Butylated hydroxyanisole, colloidal silicon dioxide, crospovidone, } \\
\text { ethyl alcohol, magnesium stearate, mannitol, microcrystalline } \\
\text { cellulose, povidone, sodium lauryl sulfate, sucrose }\end{array}$ \\
\hline
\end{tabular}

${ }^{a}$ A drug identified by the FDA as a product on which an applicant relies in seeking approval of an abbreviated new drug application for a generic product

${ }^{b}$ If bioequivalence to a reference listed drug product is demonstrated, the product will be given the same code as the reference listed drug it was compared against: AB1 vs. Unithroid, AB2 vs. Synthroid, AB3 vs. Levoxyl; AB4 vs. Levothroid/ Thyro-Tabs (now discontinued). One common code indicates therapeutic equivalence between products

c All formulations except Euthyrox also contain colorants that differ according to tablet dose

According to this Guideline, bioequivalence studies should be conducted in healthy volunteers unless the drug is associated with safety concerns that would make this unethical. In most cases, it should be possible to extrapolate the results of such studies to other populations such as the elderly, children and patients with renal or liver impairment [10].

In order to assess bioequivalence after a single dose, the Guideline recommends analyzing $\mathrm{AUC}_{(0-t)}$ or, when relevant, $\mathrm{AUC}_{(0-72 \mathrm{~h})}$, and $C_{\text {max }}$. In order to assess bioequivalence of immediate release formulations at a steady state, analysis of $\mathrm{AUC}_{(0-\tau)}$ and $C_{\max , \mathrm{ss}}$ is recommended. Bioequivalence is established when the $90 \% \mathrm{CI}$ for the ratio of the test and reference products is $\geq 80.00 \%$ and $\leq 125.00 \%$ when rounded to two decimal places. The acceptance interval may need to be narrowed to 90.00-111.11\% for products with narrow therapeutic range [10].

In Europe, medicinal products are considered to be therapeutically equivalent if they contain the same active substance or therapeutic moiety and have the same clinical efficacy and safety. Therapeutic equivalence can be established by demonstrating bioequivalence if the excipients contained within the products are generally recognized as not affecting their safety and efficacy. Bioequivalence can be established using pharmacokinetic instead of therapeutic data if, in the same individual, similar plasma concentrations over a similar 
time course will result in similar concentrations at the site of action [39].

\section{Tablet Formulations}

In the US, physicians currently have a choice of several LT4 sodium tablet preparations, five branded products and one generic formulation (Table 2) [31]. According to the US FDA system of evaluation for therapeutic equivalence, preparations with the same TE code are considered to be interchangeable (Table 2) [31, 32]. Although several LT4 products do have similar pharmacokinetic performance, this is not assured for each of the AB-rated pairs because not all have been directly compared in pharmacokinetic studies [2]. A range of LT4 tablet brand-name and generic formulations are also available in Europe and used interchangeably (brand-name products include Eltroxin, Euthyrox/Levothyrox, Thyrax, Tirosint, Eutirox, Letrox and Levaxin) $[21,38,40,41]$.

According to an analysis of US medical insurance claims data between 2007 and 2016, $73.6 \%$ of thyroid hormone prescription fills were for generic LT4 and $23.4 \%$ were for brandname LT4 (the remainder comprised other thyroid hormone drugs) [42]. The proportion of generic LT4 fills increased from 59.8\% in 2007 to $84.9 \%$ in 2016 . Prescription of brand-name LT4 was more common for women and by endocrinologists, while it was less common for elderly patients [42].

Interestingly, generic LT4 preparations are no longer used in France, partly because doctors are reluctant to prescribe them [43]. Based on the authors' experience, generic LT4 tablets are rarely used in Italy or Denmark. In addition, Danish pharmacies produce small amounts of lactose-free LT4 tablets with microcrystalline cellulose and potato starch as the only excipients present.

\section{Soft Gel and Liquid Formulations}

Soft gel and liquid LT4 formulations are alternative dosage forms of LT4 [2, 22, 37]. Lower doses of LT4 are generally required with these formulations compared with traditional tablets, because dissolution of tablet excipients does not need to occur before LT4 is available for bowel absorption [2, 44]. Soft gel and liquid formulations are preferable in patients who have reduced intestinal absorption of LT4 due to gastrointestinal disorders or concomitant drugs [41]. Any change between various LT4 formulations in such patients should be performed with special care.

Tirosint/Tiche/Syntroxine is a unique LT4 product available in the USA and Europe as a soft-gel capsule, and in Europe as a liquid formulation [2, 31, 37]. Lactose-free soft gel (LT4 dissolved in glycerin surrounded by a layer of gelatin) and liquid formulations (LT4 dissolved in glycerol and ethanol) are bioequivalent to traditional LT4 tablets in healthy volunteers, but may perform better in patients with gastrointestinal malabsorption conditions and when taken with foods and certain interacting drugs, and in patients with TSH values close to the limits of the desired therapeutic range [6, 37, 41, 44-53]. However, most studies showing better absorption with soft gel or liquid LT4 formulations compared with tablets were published after the ATA guidelines were released. As a result, there are no specific recommendations for the use of such formulations in these circumstances, but it has been suggested that they may be useful in patients with allergies or side effects to the excipients found in some LT4 tablets (e.g., lactose in Synthroid) [3, 54-56].

Caution is advised when prescribing ethanolcontaining products to certain patients, including pregnant and lactating women and patients with liver disease or epilepsy [41]. However, no adverse events were reported in a study that included 14 pregnant women treated with liquid LT4 [57]. A new oral solution free from ethanol, propylene glycol and preservatives that has been shown to be bioequivalent to Tirosint capsules has also been developed [58]. An ethanol-free liquid formulation of Eltroxin is also available in Europe, as are several generic versions [41]. However, this formulation contains sodium methyl parahydroxybenzoate as a preservative, which may cause allergic reactions, including delayed reactions [59]. 


\section{REFORMULATION}

To minimize the variability of LT4 products, the FDA now requires LT4 products to retain $95-105 \%$ of labeled LT4 content over the expected shelf life of the product instead of the previously accepted range of $90-110 \%$ [60]. The US Pharmacopeia revised their monograph for levothyroxine sodium tablets to support this change. These revisions went into effect in October 2009 [61]. The French Agence Nationale de Sécurité des Médicaments (ANSM) also requires that LT4 products retain $95-105 \%$ of LT4 content, whereas $90-105 \%$ is acceptable in the UK $[24,38]$.

Several branded products have been reformulated to meet the new standards, including Euthyrox/Levothyrox and Levoxyl tablets and Tirosint soft-gel capsules [2, 62-64]. Using the FDA criteria, the new formulations have been shown to be bioequivalent to the old formulations (Table 3) [62-64]. Geometric mean $\mathrm{AUC}_{(0-72 \mathrm{~h})}$ and $C_{\max }$ ratio $90 \%$ CIs for Euthyrox were both within the $90-111 \%$ acceptance range for narrow therapeutic index drugs $[62,63]$. The Euthyrox tablet formulation available since March 2017 no longer contains a lactose excipient, which may be beneficial for patients who are lactose-intolerant [24, 43].

\section{TSH LEVELS AFTER GENERIC SUBSTITUTION}

The TSH reference range for the general population is $0.4-4.5 \mathrm{mIU} / \mathrm{L}[1,3]$, but may increase with age (depending on dietary iodine intake), so that the upper limit is $\sim 5-6 \mathrm{mIU} / \mathrm{L}$ in patients aged $>70-90$ years [65]. For example, in Denmark, where the populations in most regions are at least mildly iodine-deficient, TSH levels do not increase with age and may actually decrease in areas with moderate iodine deficiency $[66,67]$. Considering the limitations in methodology for establishing bioequivalence for LT4 products, some variation in response (biochemical and possibly symptomatic) can be expected if patients are freely substituted from refill to refill $[2,68]$.

Between 2005 and 2007, a pharmacovigilance study was conducted by the major American endocrine societies to evaluate their members' experience with LT4 substitution [68]. At the time, four brand-name and four generic LT4 tablet preparations were available in the US. A total of 199 adverse events associated with changes in TSH values were reported. Of these, $177(88.9 \%)$ were reported after LT4 tablets had been switched [68]. The switch was made by the pharmacy in $99.4 \%$ of cases, and $91.6 \%$ of these were carried out without the physician's knowledge. There was a switch from a brand-name LT4 preparation to a generic preparation in $156(88.1 \%)$ cases, from one brand to another in $12(6.8 \%)$ and from one generic to another in 9 (5.1\%) [68]. In $11.1 \%$ of cases, adverse events were reported after refills with the same LT4 preparation, while in most cases, adverse events were reported after generic substitution for brand-name LT4. Overall, TSH values were within the expected reference range in $78.9 \%$ of patients before the reported event, whereas, at the time of the event, $47.7 \%$ exceeded the expected reference range and

Table 3 Geometric mean ratios of pharmacokinetic parameters for baseline-adjusted total plasma thyroxine after administration of new versus old formulations of levothyroxine $(600 \mu \mathrm{g})$ in healthy volunteers [70-72]

\begin{tabular}{llll}
\hline Parameter & Euthyrox & Levoxyl & Tirosint \\
\hline$C_{\max }$ & $101.7(98.8-104.6)$ & $92.5(87.1-98.2)$ & $103.1(93.5-113.6)$ \\
AUC $_{(0-48 \mathrm{~h})}$ & $\mathrm{NA}$ & $96.9(90.5-103.8)$ & NA \\
AUC $_{(0-72 \mathrm{~h})}$ & $99.3(95.6-103.2)$ & $\mathrm{NA}$ & $109.8(100.3-120.3)$ \\
\hline
\end{tabular}

$A U C_{(0-48 h)}$ area under the concentration-time curve from 0 to $48 \mathrm{~h}, A U C_{(0-72 b)}$ area under the concentration-time curve from 0 to $72 \mathrm{~h}, C_{\max }$ maximum concentration, $N A$ not assessed 
$35.2 \%$ had suppressed TSH values [68]. Symptoms suggestive of hyper- or hypothyroidism were reported [68]. Some potentially serious consequences of suboptimal LT4 therapy were identified in vulnerable populations (e.g., elderly or very young patients), most of which occurred after switching (96.3\%) [68]. However, several of the events described as serious by the reporting clinicians may not have reached the "serious" threshold in clinical trials [68]. Of note, in the US, only $9 \%$ of thyroid hormone prescriptions were made by endocrinologists according to the IMS National Prescription Audit 2009. Although not specifically assessed in this pharmacovigilance study, the cost of additional clinical activity associated with adverse clinical events after switching appear to outweigh the lower prescription costs for generic drugs $[69,70]$. Similar pharmacovigilance data are lacking in European countries, such as the UK [38].

A retrospective study of children with congenital hypothyroidism treated with either Synthroid or generic LT4 noted no difference in TSH levels or clinical outcomes, and the authors suggested that this implied interchangeability [71]. However, in an editorial published in the Journal of Clinical Endocrinology and Metabolism, Hennessey criticized this study for not directly assessing interchangeability [19]. Moreover, the generic preparation used could not be identified in $44 \%$ of patients and only $11 \%$ used an interchangeable generic preparation (the Mylan LT4 product) [19].

A prospective, randomized, cross-over trial conducted in pediatric patients with severe congenital hypothyroidism showed that TSH levels with Synthroid were significantly lower than with another AB2-rated product (Levo-T distributed as a generic and considered by the FDA to be interchangeable with Synthroid) [72]. These results were unexpected because the generic was reported to be $12.5 \%$ more bioavailable than Synthroid. These results suggest that these AB-rated products are not clinically interchangeable in patients with severe congenital hypothyroidism, and may have implications for other vulnerable populations $[19,72]$. Hennessey, in the aforementioned editorial, notes that these results highlight the limitations of the FDA protocol for establishing the bioequivalence of LT4 preparations, and suggests that further consideration should be given to the TSH-based protocol for establishing the therapeutic equivalence that was proposed by the AACE/ATA/TES $[19,73]$.

\section{PROBLEMS ENCOUNTERED AFTER FORCED SWITCHING ON A NATIONAL LEVEL}

Problems have been encountered in several countries when patients have been forced to switch LT4 products because of supply problems or mandated transition to a reformulated product that contained different excipients $[21,43,74]$.

\section{Generic or Brand Substitution}

In the Netherlands, there was a recent shortage of the most commonly used LT4 brand (Thyrax), resulting in a forced brand switch (mainly to LT4 Teva or Euthyrox) and an increase in the reported number of adverse events [21]. Although Thyrax and Euthyrox share some excipients in common (corn starch, gelatin, lactose monohydrate), most excipients are different. Thyrax Duotab 0.025-, 0.100- and 0.150-mg tablets contain talc, sodium citrate dihydrate (E 331), gelatin, glycerol (E 422), colloidal anhydrous silica (E 551), magnesium stearate (E572), as well as colorants (E132 in the $0.025-\mathrm{mg}$ tablet and E127 in the 0.150-mg tablet) [75]. Teva levothyroxine tablets contain maize starch, mannitol (E421), microcrystalline cellulose, sodium citrate, acacia and magnesium stearate [76]. Euthyrox tablets contain magnesium stearate (E 572) and croscarmellose sodium (E 468) [77]. Overall, $53 \%$ of patients using $>100 \mu \mathrm{g} /$ day showed biochemical signs of over-supplementation [21]. In response, general advice was issued to check serum TSH 6 weeks after any brand change, and to consider dose reduction for patients receiving $>100 \mu \mathrm{g} /$ day [21].

In February 2012, the UK Medicines and Healthcare products Regulatory Agency suspended the license for Teva levothyroxine $100-\mu \mathrm{g}$ tablets following reports from 
prescribers and patients describing reduced efficacy when switching from other levothyroxine products [78]. In October 2016, the suspension was lifted after Teva reformulated the tablets by making them lactose-free and changing the manufacturing process [79].

\section{Reformulation}

In 2017, a switch was made to the new formulation of Levothyrox (Euthyrox in other EU countries) in France to comply with the requirement for $95-105 \%$ potency specification, and, by 2018, there had been $>17,000$ reports of advers e events $[21,43]$. As previously mentioned, the new formulation (lactose removed and mannitol and citric acid added) had been shown to be bioequivalent to the previous formulation, and complied with the relatively stringent bioequivalence criteria for narrow therapeutic index drugs [21, 43, 63]. For adverse events with reported TSH levels, approximately $60 \%$ occurred in patients with normal TSH levels (suggesting that patients were receiving the right dose), and $15-20 \%$ in patients with TSH levels indicative of hypothyroidism or hyperthyroidism [21]. These numbers are not unusual by themselves. In a cross-sectional study conducted in the US, $60.1 \%$ of patients who were taking thyroid drugs had normal TSH, while $18.3 \%$ were hypothyroid and $21.6 \%$ were hyperthyroid [80]. There was therefore no scientific explanation for the scale of the surge in adverse events in France after the reformulation, which may have been largely fueled by poor communication (many patients were not initially informed about the change or the need to check TSH levels if they noticed any change in their overall health), social media and the nocebo effect [21, 43].

Similar problems occurred in New Zealand and Denmark a decade ago in relation to reformulated Eltroxin [21, 43, 74, 81]. A major review of the New Zealand situation also found no clear reason for the level of reported adverse events with reformulated Eltroxin [82]. Again, suggested contributing factors included poor communication and intense media interest $[74,81,82]$. Misinterpretation of the new formulation, which looked different to the old formulation may also have been a factor, i.e., a belief that the new formulation was generic leading to negative perceptions (nocebo effect) [82]. Alternative brands were made available in both countries, and the level of adverse event reporting returned to baseline, with many patients still receiving the new Eltroxin formulation [21, 74].

\section{CONCLUSIONS}

Physicians should alert patients that their LT4 prescription may be switched at the pharmacy, encourage patients to ask to remain on the same preparation at every refill, and make sure that patients understand that they need to have their TSH retested every time their LT4 product is switched $[13,19]$. In some countries, such as the USA and Denmark, physicians can state on the prescription that switching is not allowed [2].

Great care must be taken to keep clinicians and patients fully informed when a reformulated branded product is introduced, and pharmacovigilance plans should be in place to monitor adverse events [21, 24, 81].

Patients need to understand that the recommendation to stay on the same LT4 formulation is based on the concern that switching products could lead to changes in TSH that require TSH testing and dose adjustment [3].

\section{ACKNOWLEDGEMENTS}

This supplement has been sponsored by Merck.

Funding. Sponsorship for this manuscript, the Rapid Service and Open Access Fees were funded by Merck.

Medical Writing, Editorial, and Other Assistance. We would like to thank Joanne Dalton and Georgii Filatov who prepared early drafts of this manuscript on behalf of Springer Healthcare. This medical writing assistance was funded by Merck. 
Authorship. All named authors meet the International Committee of Medical Journal Editors (ICMJE) criteria for authorship for this article, take responsibility for the integrity of the work as a whole, and have given their approval for this version to be published.

Disclosures. Allan Carlé has nothing to disclose. Salvatore Benvenga has spoken at symposia organized by IBSA and has received from IBSA Institut Biochimique SA (Lugano, Switzerland) and IBSA Farmaceutici Italia s.r.l. oral liquid LT4 and soft gel LT4 for the purposes of conducting clinical studies which are cited in the reference list.

Compliance with Ethics Guidelines. This article is based on previously conducted studies and does not contain any studies with animals performed by any of the authors. Some of studies cited include analyses, or studies with human participants, performed by the authors and completed prior to the initiation of this manuscript.

Open Access. This article is distributed under the terms of the Creative Commons Attribution-NonCommercial 4.0 International License (http://creativecommons.org/licenses/ by-nc/4.0/), which permits any noncommercial use, distribution, and reproduction in any medium, provided you give appropriate credit to the original author(s) and the source, provide a link to the Creative Commons license, and indicate if changes were made.

\section{REFERENCES}

1. Garber JR, Cobin RH, Gharib H, Hennessey JV, Klein I, Mechanick JI, et al. Clinical practice guidelines for hypothyroidism in adults: cosponsored by the American Association of Clinical Endocrinologists and the American Thyroid Association. Endocr Pract. 2012;18:988-1028.

2. Hennessey JV. The emergence of levothyroxine as a treatment for hypothyroidism. Endocrine. 2017;55:6-18.

3. Jonklaas J, Bianco AC, Bauer AJ, Burman KD, Cappola AR, Celi FS, et al. Guidelines for the treatment of hypothyroidism: prepared by the American
Thyroid Association Task Force on Thyroid Hormone Replacement. Thyroid. 2014;24:1670-751.

4. Virili C, Antonelli A, Santaguida MG, Benvenga S, Centanni M. Gastrointestinal malabsorption of thyroxine. Endocr Rev. 2019;40:118-36.

5. Collier JW, Shah RB, Gupta A, Sayeed V, Habib MJ, Khan MA. Influence of formulation and processing factors on stability of levothyroxine sodium pentahydrate. AAPS PharmSciTech. 2010;11:818-25.

6. Fallahi P, Ferrari SM, Ruffilli I, Ragusa F, Biricotti M, Materazzi G, et al. Advancements in the treatment of hypothyroidism with L-T4 liquid formulation or soft gel capsule: an update. Expert Opin Drug Deliv. 2017; 14:647-55.

7. Patel H, Stalcup A, Dansereau R, Sakr A. The effect of excipients on the stability of levothyroxine sodium pentahydrate tablets. Int $\mathrm{J}$ Pharm. 2003;264:35-43.

8. Svirskis D, Lin SW, Brown H, Sangaroomthong A, Shin D, Wang Z, et al. The influence of tablet formulation, drug concentration, and $\mathrm{pH}$ modification on the stability of extemporaneously compounded levothyroxine suspensions. Int J Pharm Compd. 2018;22:164-71.

9. U.S. Food and Drug Administration. Generic Drugs: Questions \& Answers. https://www.fda.gov/Drugs/ ResourcesForYou/Consumers/QuestionsAnswers/ ucm100100.htm. Accessed 2019.

10. European Medicines Agency. Guideline on the investigation of bioequivalence. 2010. https://www. ema.europa.eu/en/documents/scientific-guideline/ guideline-investigation-bioequivalence-rev1_en.pdf. Accessed 2019.

11. Burch HB, Burman KD, Cooper DS, Hennessey JV. A 2013 survey of clinical practice patterns in the management of primary hypothyroidism. J Clin Endocrinol Metab. 2014;99:2077-85.

12. Hennessey JV. Levothyroxine dosage and the limitations of current bioequivalence standards. Nat Clin Pract Endocrinol Metab. 2006;2:474-5.

13. American Thyroid Association, Endocrine Society, American Association of Clinical Endocrinologists. Joint statement on the U.S. Food and Drug Administration's decision regarding bioequivalence of levothyroxine sodium. Thyroid. 2004;14:486.

14. Blakesley VA. Current methodology to assess bioequivalence of levothyroxine sodium products is inadequate. AAPS J. 2005;7:E42-6.

15. Bolton S. Bioequivalence studies for levothyroxine. AAPS J. 2005;7:E47-53. 
16. Garber JR, Hennessey JV. Generic levothyroxine: what is all the fuss about? Endocr Pract. $2005 ; 11: 205-7$.

17. Gibaldi M. Bioequivalence of thyroid preparations: the final word? AAPS J. 2005;7:E59-60.

18. Green WL. New questions regarding bioequivalence of levothyroxine preparations: a clinician's response. AAPS J. 2005;7:E54-8.

19. Hennessey JV. Generic vs name brand L-thyroxine products: interchangeable or still not? J Clin Endocrinol Metab. 2013;98:511-4.

20. Endocrine Society of Australia. Statement on thyroxine preparations available in Australia. https:// www.endocrinesociety.org.au/documents/ESAstat ementonthyroxine_Walshv3.docx. Accessed 2019.

21. Fliers E, Demeneix B, Bhaseen A, Brix TH. European Thyroid Association (ETA) and Thyroid Federation International (TFI) joint position statement on the interchangeability of levothyroxine products in EU countries. Eur Thyroid J. 2018;7:238-42.

22. U S Food and Drug Administration. Approved drug products with therapeutic equivalence evaluations. 38th edition 2018. http://www.fda.gov/downloads/ drugs/developmentapprovalprocess/ucm071436.pdf. Accessed 14 Dec 2018.

23. U S Food and Drug Administration. Guidance for Industry: Bioavailability and bioequivalence studies for orally administered drug products- general considerations (Draft Guidance). 2002. http://www. fda.gov/downloads/Drugs/Guidances/ucm 154838. Accessed 14 Dec 2018.

24. Lipp HP, Hostalek U. A new formulation of levothyroxine engineered to meet new specification standards. Curr Med Res Opin. 2018;35:1-4.

25. AbbVie Inc. Synthroid. Prescribing information. 2002. https://www.accessdata.fda.gov/drugsatfda docs/label/2017/021402s024s028lbl.pdf. Accessed 2019.

26. Cediprof, Inc. Levo-T. Prescribing information. 2002. https://www.accessdata.fda.gov/drugsatfda docs/label/2017/021342s023lbl.pdf. Accessed 2019.

27. Jerome Stevens Pharmaceuticals, Inc. Unithroid. Prescribing information. 2000. https://www. accessdata.fda.gov/drugsatfda_docs/label/2018/0212 10s018lbl.pdf. Accessed 2019.

28. King Pharmaceuticals, Inc. Levoxyl. Prescribing information. 2001. https://www.accessdata.fda. gov/drugsatfda_docs/label/2018/021301s038lbl.pdf. Accessed 2019.
29. Mylan Pharmaceuticals Inc. Levothyroxine sodium. Prescribing information. 2002. https://www. accessdata.fda.gov/drugsatfda_docs/label/2002/076 187lbl.pdf. Accessed 2019.

30. Provell Pharmaceuticals, LLC. Euthyrox. Prescribing information. 2002. https://www.accessdata.fda. gov/drugsatfda_docs/label/2018/021292s004,02129 2s005,021292s006lbl.pdf. Accessed 2019.

31. U S Food and Drug Administration. Orange book: approved drug products with therapeutic equivalence evaluations http://www.accessdata.fda.gov/ scripts/cder/ob/index.cfm. Accessed 14 Dec 2018.

32. U.S. Food and Drug Administration. Approved drug products with therapeutic equivalence evaluations. 39th edition 2019. https://www.fda.gov/ downloads/Drugs/DevelopmentApprovalProcess/UC M071436.pdf. Accessed 2019.

33. U.S. Food and Drug Administration. Approved drug products with therapeutic equivalence evaluations. 39th edition. Cumulative supplement 2. 2019. https://www.fda.gov/downloads/Drugs/Informatio nOnDrugs/UCM086233.pdf. Accessed 2019.

34. Mayor GH, Orlando T, Kurtz NM. Limitations of levothyroxine bioequivalence evaluation: analysis of an attempted study. Am J Ther. 1995;2:417-32.

35. Dong BJ, Hauck WW, Gambertoglio JG, Gee L, White JR, Bubp JL, et al. Bioequivalence of generic and brand-name levothyroxine products in the treatment of hypothyroidism. JAMA. 1997;277:1205-13.

36. Benvenga S, Bartolone L, Squadrito S, Lo Giudice F, Trimarchi F. Delayed intestinal absorption of levothyroxine. Thyroid. 1995;5:249-53.

37. Al-Numani D, Scarsi C, Ducharme MP. Levothyroxine soft capsules demonstrate bioequivalent pharmacokinetic exposure with the European reference tablets in healthy volunteers under fasting conditions. Int $\mathrm{J}$ Clin Pharmacol Ther. 2016;54:135-43.

38. Medicines and Healthcare Products Regulatory Agency (MHRA). Levothyroxine tablet products: a review of clinical \& quality considerations. 2013. http://www.gov.uk/government/publications/levot hyroxine-a-review-of-clinical-and-quality-considera tions. Accessed 14 Dec 2018.

39. The European Agency for the Evaluation of Medicinal Products. Note for Guidance on the Investigation of Bioavailability and Bioequivalence. 2000. https://www.ema.europa.eu/en/documents/scientif ic-guideline/draft-note-guidance-investigation-bioa vailability-bioequivalence_en.pdf. Accessed 2019. 
40. Colucci P, Yue CS, Ducharme M, Benvenga S. A review of the pharmacokinetics of levothyroxine for the treatment of hypothyroidism. Eur Endocrinol. 2013;9:40-7.

41. Vita R, Fallahi P, Antonelli A, Benvenga S. The administration of L-thyroxine as soft gel capsule or liquid solution. Expert Opin Drug Deliv. 2014;11:1103-11.

42. Ross JS, Rohde S, Sangaralingham L, Brito JP, Choi L, Dutcher SK, et al. Generic and brand-name thyroid hormone drug use among commercially-insured and medicare beneficiaries, 2007-2016. J Clin Endocrinol Metab. 2019.

43. Casassus B. Risks of reformulation: french patients complain after Merck modifies levothyroxine pills. BMJ. 2018;360:k714.

44. Virili C, Trimboli P, Romanelli F, Centanni M. Liquid and softgel levothyroxine use in clinical practice: state of the art. Endocrine. 2016;54:3-14.

45. Brancato D, Scorsone A, Saura G, Ferrara L, Di Noto A, Aiello V, et al. Comparison of TSH levels with liquid formulation versus tablet formulations of levothyroxine in the treatment of adult hypothyroidism. Endocr Pract. 2014;20:657-62.

46. Di Donna V, Paragliola RM, de Waure C, Papi G, Pontecorvi A, Corsello SM. Is levothyroxine requirement the same for tablet and soft gel formulations? Endocrine. 2018;59:458-60.

47. Fallahi P, Ferrari SM, Antonelli A. Oral L-thyroxine liquid versus tablet in patients with hypothyroidism without malabsorption: a prospective study. Endocrine. 2016;52:597-601.

48. Fallahi P, Ferrari SM, Antonelli A. In patients with subclinical hypothyroidism while in therapy with tablet L-T4, the liquid L-T4 formulation is more effective in restoring euthyroidism. Endocr Pract. 2017;23:170-4.

49. Fallahi P, Ferrari SM, Camastra S, Politti U, Ruffilli I, Vita R, et al. TSH normalization in bariatric surgery patients after the switch from L-thyroxine in tablet to an oral liquid formulation. Obes Surg. 2017;27:78-82.

50. Guglielmi V, Bellia A, Bianchini E, Medea G, Cricelli I, Sbraccia P, et al. Drug interactions in users of tablet vs. oral liquid levothyroxine formulations: a real-world evidence study in primary care. Endocrine. 2018;59:585-92.

51. Trimboli P, Virili C, Centanni M, Giovanella L. Thyroxine treatment with softgel capsule formulation: usefulness in hypothyroid patients without malabsorption. Front Endocrinol (Lausanne). 2018;9:118.

52. Virili C, Giovanella L, Fallahi P, Antonelli A, Santaguida MG, Centanni $\mathrm{M}$, et al. Levothyroxine therapy: changes of TSH levels by switching patients from tablet to liquid formulation. A systematic review and meta-analysis. Front Endocrinol (Lausanne). 2018;9:10.

53. Vita R, Di Bari F, Benvenga S. Oral liquid levothyroxine solves the problem of tablet levothyroxine malabsorption due to concomitant intake of multiple drugs. Expert Opin Drug Deliv. 2017;14:467-72.

54. Espaillat R, Jarvis MF, Torkelson C, Sinclair B. Gluten and aluminum content in Synthroid ${ }^{\circledR}$ (levothyroxine sodium tablets). Adv Ther. 2017;34:1764-9.

55. Fallahi P, Ferrari SM, Marchi S, De Bortoli N, Ruffilli I, Antonelli A. Patients with lactose intolerance absorb liquid levothyroxine better than tablet levothyroxine. Endocrine. 2017;57:175-8.

56. Jonklaas J. Update on the treatment of hypothyroidism. Curr Opin Oncol. 2016;28:18-25.

57. Cappelli C, Negro R, Pirola I, Gandossi E, Agosti B, Castellano M. Levothyroxine liquid solution versus tablet form for replacement treatment in pregnant women. Gynecol Endocrinol. 2016;32:290-2.

58. Tanguay M, Girard J, Scarsi C, Mautone G, Larouche R. Pharmacokinetics and comparative bioavailability of a levothyroxine sodium oral solution and soft capsule. Clin Pharmacol Drug Dev. 2018;8:521-8.

59. Electronic Medicines Compendium (eMC). Eltroxin 100 micrograms per $5 \mathrm{ml}$ oral solution. 2013. https://www.medicines.org.uk/emc/product/4305/ smpc. Accessed 2019.

60. Burman K, Hennessey J, McDermott M, Wartofsky L, Emerson C. The FDA revises requirements for levothyroxine products. Thyroid. 2008;18:487-90.

61. United States Pharmacopeia, National Formulary. USP Announces a Revised Monograph For Levothyroxine Sodium Tablets. 2008. https://www. uspnf.com/notices/retired-compendial-notices/uspannounces-revised-monograph-levothyroxine-sodi um-tablets. Accessed 2019.

62. Colucci P, D'Angelo P, Mautone G, Scarsi C, Ducharme MP. Pharmacokinetic equivalence of a levothyroxine sodium soft capsule manufactured using the new food and drug administration potency guidelines in healthy volunteers under 
fasting conditions. Ther Drug Monit. 2011;33:355-61.

63. Gottwald-Hostalek U, Uhl W, Wolna P, Kahaly GJ. New levothyroxine formulation meeting 95-105\% specification over the whole shelf-life: results from two pharmacokinetic trials. Curr Med Res Opin. 2017;33:169-74.

64. Grant TM, Zhu Y, Brandquist C, Teuscher NS, Lamson MJ. Randomized, open-label, single-dose, two-way crossover study to determine the relative bioavailability of a reformulated levothyroxine tablet compared with the commercial tablet $\left(\right.$ Levoxyl $\left.{ }^{\circledR}\right)$ in healthy volunteers. Clin Pharmacol Ther. 2009;85:S95 (abstract PIII-85).

65. Calsolaro V, Niccolai F, Pasqualetti G, Tognini S, Magno S, Riccioni T, et al. Hypothyroidism in the elderly: who should be treated and how? J Endocr Soc. $2019 ; 3: 146-58$.

66. Knudsen N, Bulow I, Jorgensen $\mathrm{T}$, Laurberg $\mathrm{P}$, Ovesen L, Perrild H. Comparative study of thyroid function and types of thyroid dysfunction in two areas in Denmark with slightly different iodine status. Eur J Endocrinol. 2000;143:485-91.

67. Knudsen N, Jorgensen T, Rasmussen S, Christiansen E, Perrild $\mathrm{H}$. The prevalence of thyroid dysfunction in a population with borderline iodine deficiency. Clin Endocrinol. 1999;51:361-7.

68. Hennessey JV, Malabanan AO, Haugen BR, Levy EG. Adverse event reporting in patients treated with levothyroxine: results of the pharmacovigilance task force survey of the American Thyroid Association, American Association of Clinical Endocrinologists, and the Endocrine Society. Endocr Pract. 2010;16:357-70.

69. Katz M, Scherger J, Conard S, Montejano L, Chang S. Healthcare costs associated with switching from brand to generic levothyroxine. Am Health Drug Benefits. 2010;3:127-34.

70. Khandelwal N, Johns B, Hepp Z, Castelli-Haley J. The economic impact of switching from Synthroid for the treatment of hypothyroidism. J Med Econ. 2018;21:518-24.

71. Lomenick JP, Wang L, Ampah SB, Saville BR, Greenwald FI. Generic levothyroxine compared with synthroid in young children with congenital hypothyroidism. J Clin Endocrinol Metab. 2013;98:653-8.

72. Carswell JM, Gordon JH, Popovsky E, Hale A, Brown RS. Generic and brand-name L-thyroxine are not bioequivalent for children with severe congenital hypothyroidism. J Clin Endocrinol Metab. 2013;98:610-7.

73. Eisenberg M, Distefano JJ. TSH-based protocol, tablet instability, and absorption effects on L-T4 bioequivalence. Thyroid. 2009;19:103-10.

74. Faasse $\mathrm{K}$, Cundy $\mathrm{T}$, Petrie KJ. Medicine and the media. Thyroxine: anatomy of a health scare. BMJ. 2009;339:b5613.

75. Aspen Pharma Trading Limited. Thyrax Duotab. Summary of product characteristics [document in Dutch]. https://db.cbg-meb.nl/Bijsluiters/h08389. pdf. Accessed 2019.

76. Teva UK Limited. Levothyroxine tablets. Summary of product characteristics. 2016. https://www. tevauk.com/mediafile/id/46017.pdf. Accessed 2019.

77. Merck BV. Euthyrox. Summary of product characteristics [document in Dutch]. 1982. https://www. merckgroup.com/content/dam/web/corporate/nonimages/country-specifics/netherlands/euthyrox/NL $\% 20$ SPC\%20levothyroxine\%20Euthyrox\%20tablets \%202017Oct15\%20nl\%202.0.pdf. Accessed 2019.

78. Medicines and Healthcare Products Regulatory Agency (MHRA). Teva levothyroxine 100 microgram tablets: suspension of marketing authorisation. 2014. https://www.gov.uk/drug-safetyupdate/teva-levothyroxine-100-microgram-tabletssuspension-of-marketing-authorisation. Accessed 2019.

79. Medicines and Healthcare Products Regulatory Agency (MHRA). Teva levothyroxine tablets: re-entry to market and introduction of new tablet strengths. 2016. https://www.gov.uk/government/ news/teva-levothyroxine-tablets-re-entry-to-marketand-introduction-of-new-tablet-strengths. Accessed 2019.

80. Canaris GJ, Manowitz NR, Mayor G, Ridgway EC. The Colorado thyroid disease prevalence study. Arch Intern Med. 2000;160:526-34.

81. Dew K, Gardner J, Morrato EH, Norris P, Chamberlain $\mathrm{K}$, Hodgetts D, et al. Public engagement and the role of the media in post-marketing drug safety: the case of Eltroxin ${ }^{\circledR}$ (levothyroxine) in New Zealand. Crit Public Health. 2018;28:388-401.

82. Medicines and Healthcare Products Regulatory Agency (MHRA). Expert review of Medsafe's pre-licensing Assessment and Pharmacovigilance Activities for a new formulation of Eltroxin $50 \mathrm{mcg}$ and 100 mcg tablets: conducted by the UK MHRA and Regulatory Agency for the New Zealand Ministry of Health. 2009. http://medsafe.govt.nz/hot/alerts/ MHRA\%20Report.pdf. Accessed 14 Dec 2018. 